\title{
基于 GIS 的不动产测绘具体应用
}

\section{Specific Application of Real Estate Surveying and Mapping Based on GIS \\ 王芹}

Qin Wang

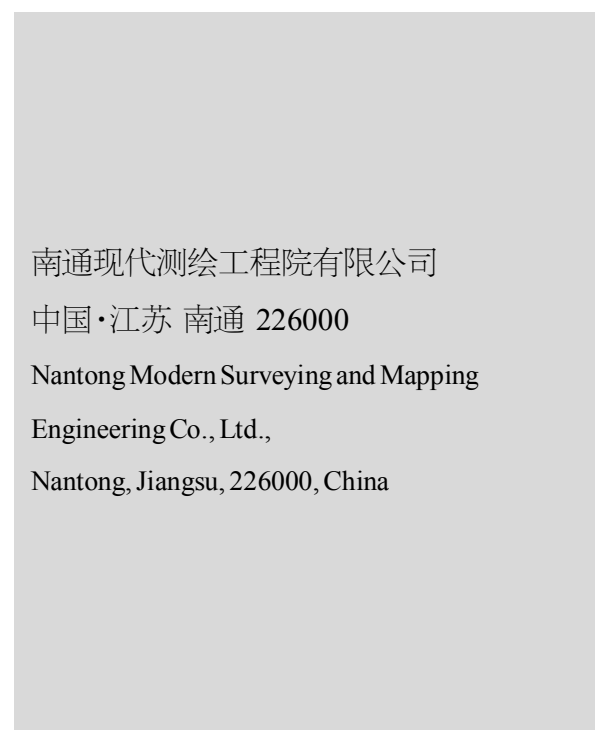

\section{1 引言}

在现代化社会的发展中,土地利用逐渐呈现出立体化、复 杂化的发展趋势, 相关部门必须加强对不动产相关工作的重 视, 实现不动产测绘、不动产管理、不动产登记等工作向立体 化模式进行转变。为了满足现代化社会的发展需求, 相关部门 应强化不动产测绘工作力度, 引进 GIS 技术, 直观地展现出 地、楼、房之间的空间关系。基于此, 本文介绍了不动产测绘的 相关内容, 分析了 GIS 在不动产测绘中的应用, 总结了基于 GIS 的不动产测绘具体应用实例。

\section{2 不动产测绘的相关内容}

\section{1 不动产测绘概述}

在新时期的快速发展中, 不动产测绘为土地房产管理工 作的有效实施提供了依据，这项技术的应用有助于获取更多 准确的数据, 为后期测绘工作的顺利开展提供保障。不动产测 绘范围的重点是地籍测量、地籍图测绘、利用测量绘图针对测 量变量进行控制, 图 1 介绍了地籍测量工作流程图。

\section{2 不动产测绘的特点}

\subsection{1 比例尺与目标不同}

通常情况下, 不动产测绘工作在室外完成, 其内容呈现出 复杂性、全面性、大范围特点。在不动产测绘过程中, 技术人员

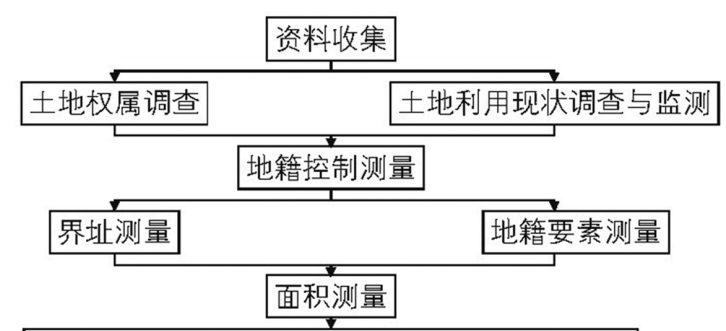

地籍成果图绘制( 地籍分幅图、宗地图、面积数据)

图 1 地籍测量工作流程图

需要在不动产测绘方案中, 针对各个区域进行标注, 这就使得 不动产测绘比例尺比常规图纸比例尺大 ${ }^{[1]}$ 。并且, 不动产测绘 目标也存在很大差异, 其主要测绘内容是房屋位置、数量、属 性、周边地质情况。

\subsection{2 权威性}

在不动产测绘过程中, 相关人员需要严格按照国家法律 法规进行, 其主要依据是国家规范性文件、标准的测量仪器, 专业技术人员参与测绘工作的过程中, 获取更多准确的测量 结果、资料, 如房产原始档案。另外, 不动产测绘工作需要相关 部门审批, 不能出现随意更改、估算的问题, 如房产测绘结果 可以为房产提供法律支持。因此, 不动产测绘结果比较权威, 为后期房产出售、转让等变更工作提供依据。

2.2 .3 对测绘人员技术要求比较高

随着城市化建设的日益推进, 不动产测绘工作的重要性 
地籍测绘 Cadastral Surveying and Mapping

不断显现出来, 这就对不动产测绘人员技术提出了更加严格 的要求, 不动产测绘人员逐渐成为不动产公平交易的鉴定者, 需要掌握测绘、重新测绘不动产拆迁、变更工作内容, 测绘人 员必须提升自身的综合素质。因此,在新时期的发展中,不动 产测绘人员应明确测绘流程、技术方法, 掌握不动产相关的业 务知识, 获取更多准确的不动产测绘结果, 促使不动产测绘工 作的有效开展, 提高不动产测绘的整体水平。

\section{GIS 在不动产测绘中的应用}

\section{1 实时动态定位}

在不动产测绘过程中, 实时动态定位技术发挥着十分重 要的作用,其重点是基准站、流动站,利用无线数据通信可以 实时进行动态测量。在实际测量过程中, 技术人员应将快速静 态定位、动态定位两种测量模式融合起来, 有效地开展工程勘 测、施工放样、监督管理、数据采集等工作。在不动产测量过程 中, 开发土地实时测量、界桩位置测定、土地面积计算都能够 利用实时动态定位技术完成，这项技术无须利用解析法进行 放样, 在很大程度上简化了勘测程。

\section{2 获取立体的测量信息}

在应用 GIS 技术的过程中, 需要大量测绘数据作为依据, 充分发挥出统计汶览、输出的作用, 以此计算出测量区域的各 项信息, 如测量区域内需要变更的土地、小区住宅容积率、建筑 物空间利用等,随后应用到后期规划工作中,在统计这些数据 信息后,工作人员汶览信息更加便利,并针对显示的图形数据 进行控制, 可以显示出建筑物及该位置的地籍图。另外, GIS 系 统还支持输出,如打印详细的地形图、三维立体图,这项技术的 应用范围比较广泛、功能强大, 主要将 ArcGIS 作为开发平台, 将获取的房产数据输入 GIS 房产数据库中, 缩短了开发周期[1]。 并且, GIS 技术跟踪、图形扫描等功能, 为输人、编辑不动产数据 提供了便利, 还能够修改、更新各项数据, 将获取的数据转变成 矢量格式、栅格的格式空间,完成数据投影、建立模型等操作。

\section{3 查询测绘信息}

在不动产测绘过程中, GIS 系统的应用能够调用空间数 据文件、属性数据文件, 技术人员必须掌握 GIS 技术的应用方 法, 发挥出这项技术的分析功能、属性处理功能, 实现不动产 数据、属性数据之间的关联性, 其空间分析功能在很大程度上 满足了用户对不动产数据实时访问的需求，可以高效获取更 多查询结果, 为各项决策工作提供依据。

\section{4 基于 GIS 的不动产测绘应用实例}

在某地区房产管理过程中，相关部门仍实行传统的测图
技术，这项技术主要以专职数据采集型从业人员提供的数据 为准, 已无法满足新时期的管理需求, 传统的房产数据库只针 对属性进行管理, 导致管理图形的弊端日益显现出来, 很难适 应新时期房产管理的发展。为了有效地改善这一现状,测绘部 门针对房产调查、外业数据采集、测图等工作进行了优化, 实 行数字化房产测量工作, 开发了适应区域发展的房产信息管 理系统,并取得了一定的成果,具体如下。

\section{1 房产调查}

在房产调查过程中, 测绘部门针对房屋进行了实地勘丈, 丈量房屋边长进行了实地丈量, 减少了测量数据的误差, 精 度: 单点定位为 $5 \mathrm{~m}, \mathrm{SBAS}$ 为 $1 \sim 2 \mathrm{~m}$, 差分后处理为 $1 \mathrm{~m}$, 静态测 量为 $\pm 5 \mathrm{~mm}+1 \times 10^{-6}$, 获取了更多准确的测量信息, 对比传统方 式精度提升了 $40 \%$ 以上。

\section{2 面积量算}

测绘技术人员通过应用 GIS 系统, 节省了很多计算时间, 对比传统测量方式,一周的面积计算时间可以在一天内完成, 节省了很多的时间、成本, 能够提前完成测量工作, 且节省的 时间可以完成其他各项测量任务。

\section{3 信息系统实现}

在实际测绘过程中，技术人员将现有的 GIS 软件作为平 台, 进行二次开发, 实现了房产 GIS 信息系统的基本功能, 为 数据输入、查询显示、数据统计、打印输出提供了便利, 缓解了 操作人员的压力, 节省了大量的人力资源成本, 由原来的 8 人 降低为 3 人 $^{[3]}$ 。

\section{5 结语}

综上所述, 随着社会经济的快速发展, 中国房地产市场发 展十分迅速，房地产信息化建设逐渐成为新时期发展的重要 趋势。不动产测绘是获取房产管理数据的关键方式, 在房产信 息化建设中发挥着重要作用。为了满足新时期的发展需求, 技 术人员必须注重 GIS 技术的应用，这项技术的应用可以节省 更多的人力资源、设备成本, 获取更多准确的不动产测绘信 息, 提高测绘工作的整体效率,为房地产行业的持续、稳定发 展提供保障。

\section{参考文献}

[1]梁铭,刘如.基于 GIS 的不动产权籍管理系统的设计与实现 以惠州市为例 [J].测绘与空间地理信息,2020,43(5):112-115.

[2]魏生文. 房产测绘与数据管理中的 GIS 技术应用探究 [J].价值 工程,2020,39(10):222-224.

[3]穆超,孟丹,谢菲.三维 GIS 在地籍管理中的应用研究[J].工程 建设与设计,2019(6):278-280。 